\title{
Removal of Nickel (II) and Cobalt (II) from Wastewater Using Vinegar-Treated Eggshell Waste Biomass
}

\author{
Morlu Stevens*, Bareki Batlokwa \\ Department of Chemical and Forensic Sciences, Botswana International University of Science and Technology, Palapye, Botswana \\ Email: *morlu.stevens@studentmail.biust.ac.bw, batlokwab@biust.ac.bw
}

How to cite this paper: Stevens, M. and Batlokwa, B. (2017) Removal of Nickel (II) and Cobalt (II) from Wastewater Using Vinegar-Treated Eggshell Waste Biomass. Journal of Water Resource and Protection, 9, 931-944.

https://doi.org/10.4236/jwarp.2017.98062

Received: May 13, 2017

Accepted: June 30, 2017

Published: July 3, 2017

Copyright (๑) 2017 by authors and Scientific Research Publishing Inc. This work is licensed under the Creative Commons Attribution International License (CC BY 4.0).

http://creativecommons.org/licenses/by/4.0/

(c) †) Open Access

\begin{abstract}
The use of waste materials as low-cost adsorbents is attractive due to their contribution in the reduction of costs for waste disposal, therefore contributing to environmental protection and most importantly, offers an attractive potential alternative to their conventional methods of removal of toxic ions from wastewater. Eggshells are naturally occurring and an abundant biomass that has proven to offer an economic solution for toxic ions removal. The eggshell biomass was treated with acetic acid (vinegar). Nickel (II) and Cobalt (II) ions were selected as model ions to demonstrate the potential of eggshell waste in removing excess toxic heavy metal ions from wastewater. All the experiments were carried out in batch process with laboratory prepared samples. Multivariate optimization method was used to identify factors affecting adsorption. These factors included metal ion concentration, $\mathrm{pH}$, contact time and biomass dosage on removal of nickel and cobalt from wastewater effluent was investigated. Two-level fraction factorial and central composite design were used for optimization methods. Fourier Transform Infrared Spectroscopy, Raman Spectroscopy, and Scanning Electron Microscopy coupled with Energy-dispersive X-ray spectroscopy were used to study physical properties of the waste material. The percentage removal of Nickel (II) and Cobalt (II) was $78.70 \pm 1.02$ and $76.53 \pm 1.21$ respectively. Vinegar-treated eggshells were proposed as eco-friendly, cheap, easily available and an efficient method for removal of heavy metals from the environment.
\end{abstract}

\section{Keywords}

Nickel, Cobalt, Vinegar-Treated, Biomass, Eggshells, Wastewater, Optimization, Adsorption 


\section{Introduction}

Scientists seek to understand the complex interactions of pollutants within the environment so that the present condition of the ambient environment can be assessed and measures taken to prevent or minimize future degradation. One important element of this dynamic system is the heavy metal pollution. Heavy metals are produced from a variety of natural and anthropogenic sources. In fluvial environments, metal pollution results from direct atmospheric deposition, geologic weathering or through the discharge of agricultural, municipal, residential or industrial waste products [1].

Heavy metals are reported to inhibit nitrification and denitrification processes [2] [3]. The toxicity of heavy metals in wastewater is shown to depend on factors such as metal species and concentration, $\mathrm{pH}$, sludge concentration, wastewater pollution load [4] [5] and solubility of the metal ions [6].

Various regulatory bodies have set the maximum prescribed limits for the discharge of toxic heavy metals in the aquatic systems. However, the metal ions are being added to the water stream at a much higher concentration than the prescribed limits by industrial activities, thus leading to health hazards and environmental degradation. Nickel is toxic heavy metal pollutant which is present in effluents of electroplating industries. Studies of human cell cultures have indicated that nickel is a possible carcinogen, creating a need for the environmental cleanup. Cobalt is also released to the environment from burning coal and oil, from car, truck and airplane exhausts, and from industrial processes that use the metal or its compounds.

The conventional methods for metal removal from water include reduction, precipitation, ion exchange, electrochemical reduction, and reverse osmosis [7] [8] [9] [10]. Most of them involve high capital costs with recurring expenses, which are not suitable for small-scale industries. Studies on treatment of metal-bearing effluents have revealed adsorption to be effective among the physicochemical processes [11] [12] [13]. Adsorption with activated carbon is widely applied for removal of heavy metals at trace levels [14].

The biomass from eggshells can be processed and converted to be adsorbents because they have large surface areas, high swelling capacities, and excellent mechanical strengths and are convenient to use and have great potential to adsorb harmful contaminants such as heavy metals. In this study, vinegar-treated eggshell (VTE) biomass was employed for the removal of nickel and cobalt.

\section{Materials and Methods}

\subsection{Materials}

The adsorbent used for the experiments were brown eggs shells collected from Palapye, Botswana. Ultra-pure water of $18.0 \mathrm{M} \Omega / \mathrm{cm}$ resistivity was used to prepare all solutions. Reagents used were: analytical grade $\mathrm{HCl}(37 \%)$ and $\mathrm{HNO}_{3}$ (60\%) purchased from ACE (Johannesburg, South Africa), SPAR white spirit Vinegar, which was employed to treat the waste materials, was purchased from SPAR (Palapye, Botswana). Elemental standard solutions used (1000 ppm-Co 
and $\mathrm{Ni}$ ) and $\mathrm{NaOH}(97 \%)$ pellets were purchased from Rochelle Chemicals (Johannesburg, South Africa). The $0.45 \mu \mathrm{m}$ pore sized Whatman filter papers (Hardened Ashless Circles $45 \mathrm{~mm}$ ) that was used for all filtering processes were purchased from Sigma-Aldrich (Johannesburg, South Africa).

\subsection{Instrumentation}

For determination of size, morphology and nanoparticle composition, JSM 1700 SEM coupled with EDX, obtained from USA was used and Perkin Elmer System, Spectrum two Fourier transform infrared (FTIR) spectroscopy was used to determine the functional groups of materials. Additional investigation on the chemical property of the adsorbents was carried out employing a LabRAM HR Evolution Raman S0-TNO4 Spectrometer (Jobin YVon Technology, France) obtained from Jobin YVon Technology (Villeneuve d'Ascg, France). All cations were determined by an iCAP 7000 series Thermo Scientific inductively coupled plasma spectrometer (ICP-OES), (Johannesburg, South Africa).

\subsection{Preparation of Eggshells Prior to Application}

The brown egg shells were washed thoroughly with deionized water to remove dust and other impurities. They were then it was sun dried for $48 \mathrm{hrs}$ and pulverized employing a Fritsch pulverisette 5 pulveriser obtained from Fritsch (Berlin, Germany), operated at $400 \mathrm{rpm}$ for $45 \mathrm{~min}$ in both milling and reverse mode. The pulverized materials were then sieved to 62 - 200-micron mesh size. After screening they were again washed with deionized water several times to remove color and dust. The material was than treated with SPAR white spirit vinegar to remove inorganic pollutants. Finally, they were dried in an oven at $65^{\circ} \mathrm{C} \pm 5^{\circ} \mathrm{C}$ for $6 \mathrm{hrs}$.

To evaluate and reveal details on the physical and chemical properties of the eggshell biomass materials, Fourier transform infrared spectroscopy (FT-IR), scanning electron microscopy coupled with energy dispersive X-ray spectroscopy (SEM-EDX) and Raman spectroscopy were employed for the characterization.

\subsection{Determination of Co and Ni in Treated Eggshell Biomass}

$3 \mathrm{~g}$ of the treated and that of the untreated egg shells was weighed and then digested employing a MARS6 microwave assisted digester in an aqua regia solution of $\mathrm{HCl}: \mathrm{HNO}_{3}$ at a ratio of 3:1 v/v. Each mixture was placed in $100 \mathrm{~mL}$ TFM sample vessel and digested at a pressure of $600 \mathrm{psi}$, temperature of $100^{\circ} \mathrm{C}$ and $1200 \mathrm{~W}$. The ramp time was set at $20.0 \mathrm{~min}$ with a hold time of $10.0 \mathrm{~min}$. The resulting volume was filtered using a Whatman No. 1 filter paper and put into 50 $\mathrm{mL}$ volumetric flasks. Deionized water was added to the flasks and filled up to the mark. The samples were investigated for cations employing ICP-OES.

\subsection{Batch Adsorption Studies for Metal Removal Using Treated Eggshell Biomass}

All experiments were carried out in batches and done in triplicates. A $100 \mathrm{mg} / \mathrm{L}$ 
standard mixture of $\mathrm{Co}$ and $\mathrm{Ni}$ was prepared from $1000 \mathrm{ppm}$ stock solution of each of the cations. The biomass material employed was of particle size of $\leq 63$ $\mu \mathrm{m}$.

\subsection{Optimization of Adsorptive Parameters of Treated Eggshell Biomass}

Optimization studies were carried out using multivariate optimization methodology. In this study, the biomass material was optimized by looking at four factors, namely contact time, $\mathrm{pH}$, biomass dosage, as well as concentration. These were first screened through the use of a two-level fractional factorial design. This enabled identification of the significance of each factor towards the experimental output. Following this, a face centered central composite design was then performed to determine the optimum conditions for each factor that would result in a maximized response of the experiments. The optimization process was carried out with the use of Minitab Release 14 statistical software (Minitab Inc., USA).

\subsection{Two-Level $1 / 2$ Fraction Factorial Design}

The screening design was carried using the experimental conditions as described in Table 1. It was then filtered into a $50 \mathrm{~mL}$ volumetric flask and deionized water added to the mark. It was investigated for cations employing ICP-OES. The experiments were done in triplicates to evaluate the adequacy of the method and lack-of-fit.

\subsection{Central Composite Design (CCD)}

The CCD was used as the experimental matrix for the response surface method. The significant factors from the screening phase (two-level $1 / 2$ fraction factorial design) were all used for the optimization phase (CCD). Two replicates were also carried out for this set of experiments. It was then filtered into a $50 \mathrm{~mL}$ volumetric flask and deionized water added to the mark. It was investigated for cations employing ICP-OES.

\subsection{Determination of $\mathrm{Co}$ and $\mathrm{Ni}$ in Wastewater Sample}

$50 \mathrm{~mL}$ of the wastewater sample was measured and added to an aqua regia solution of $\mathrm{HCl}: \mathrm{HNO}_{3}$ at a ratio of 3:1 v/v. The mixture was transferred to a $100 \mathrm{~mL}$

Table 1. Factors and their levels for the two-level fractional factorial design for the optimization of the eggshell biomass.

\begin{tabular}{cccc}
\hline Variable & Factor & Low level & High level \\
\hline A & Dosage $(\mathrm{mg})$ & 25 & 100 \\
B & $\mathrm{pH}$ & 2 & 10 \\
C & Contact time (minutes) & 15 & 90 \\
D & Concentration (mg/L) & 0 & 50 \\
\hline
\end{tabular}


TFM sample vessel and then digested employing a MARS6 microwave assisted digester operated at a pressure of $600 \mathrm{psi}$, temperature of $100^{\circ} \mathrm{C}$ and $1200 \mathrm{~W}$. The ramp time was set at $20.0 \mathrm{~min}$ with a hold time of $10.0 \mathrm{~min}$. The resulting volume was transferred to $50 \mathrm{~mL}$ volumetric flasks. Deionized water was added to the flasks and filled up to the mark. The samples were investigated for cations and employing ICP-OES.

\subsection{Application of the Optimized Adsorption Method to Real Samples}

The extraction efficiency of the treated eggshells was determined by applying the optimized parameters (see Table 2) to wastewater samples collected from sewage treatment plant. Egg shells biomass were used for the ions Co and Ni removal in the samples. $50 \mathrm{~mL}$ of water samples were used and the optimized conditions applied to the water samples. The mixture was subjected to a rotary shaker at $200 \mathrm{rpm}$ for the optimized time, after which it was then filtered using a whatman No. 1 filter paper and put into $50 \mathrm{~mL}$ volumetric flasks. Deionized water was added to the flasks and filled up to the mark. The analysis was done in triplicates, and a series of ions (Co and $\mathrm{Ni}$ ) standards (from $5 \mathrm{ppm}$ to $50 \mathrm{ppm}$ ) were prepared for the calibration curve. The analytes remaining in the water sample after adsorption were determined with ICP-OES; the results were analyzed using Microsoft Excel 2016.

\section{Results}

\subsection{Scanning Electron Microscopy Coupled with Energy Dispersive X-Ray Spectroscopy (SEM-EDX)}

As observed the eggshell waste powder particles have irregular shape, resulting of the comminution process used. The micrographs show high porosity of the eggshell powder particles (TEs). It also appears to have a rough surface and is characterized by having two regions, one being darker and the other being white. The white region is rich in inorganic material containing high proportion of calcium, whereas the dark region is rich in protein because it has high proportion of carbon and oxygen. From energy, dispersive X-ray (EDX) analysis, inorganic ions were confirmed in the eggshell powder before treatment and after adsorption. Figure 1(b) clearly shows that the presence of new shiny bulky particles over the surface of ions loaded eggshell (AEs) which are absent in the VTE (Figure 1(a)). These results confirm the binding of ions in eggshell powder through adsorption.

Table 2. Optimization parameters.

\begin{tabular}{ccccc}
\hline & $\mathrm{pH}$ & Sorbent dose $(\mathrm{mg})$ & Contact time $(\mathrm{min})$ & Conc $(\mathrm{mg} / \mathrm{L})$ \\
\hline $\mathrm{Co}$ & 7.49 & 77.41 & 64.81 & 21.41 \\
$\mathrm{Ni}$ & 8.07 & 80.64 & 73.01 & 25.06 \\
\hline
\end{tabular}




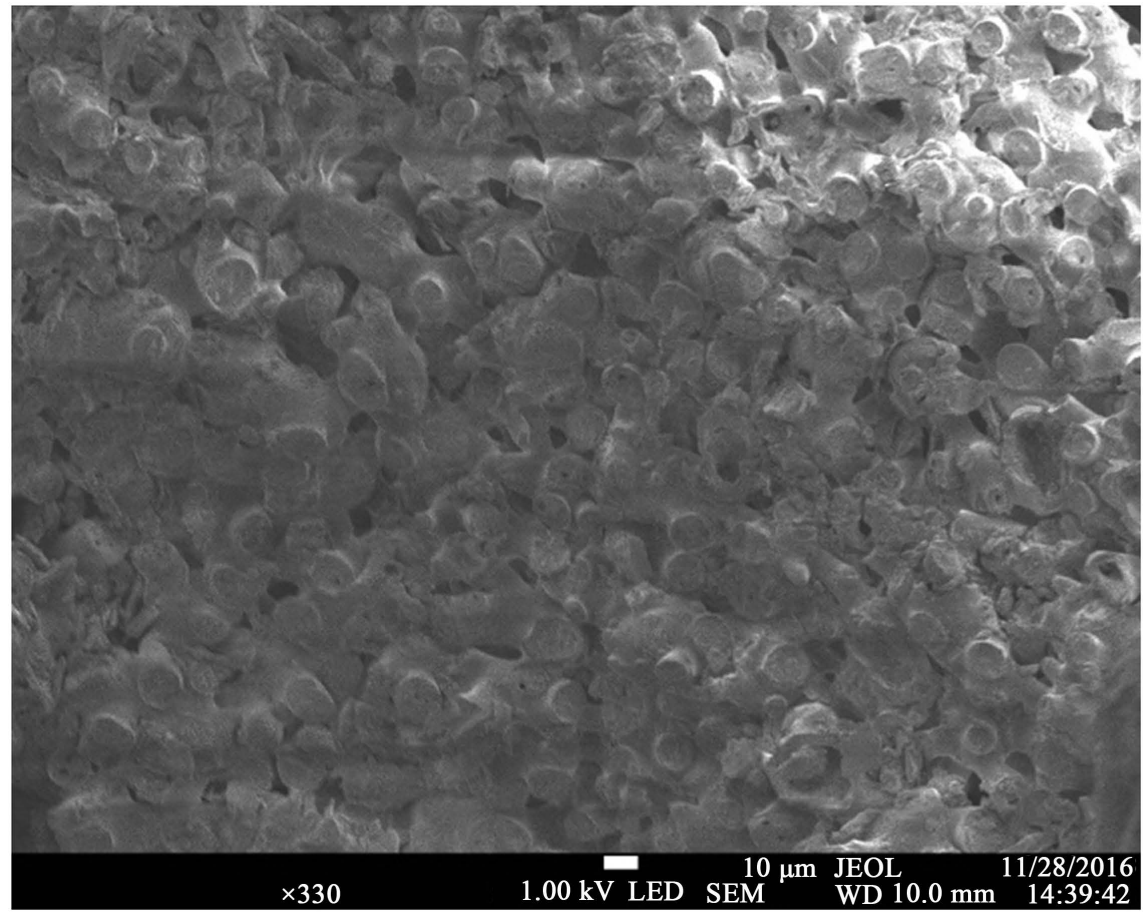

(a)

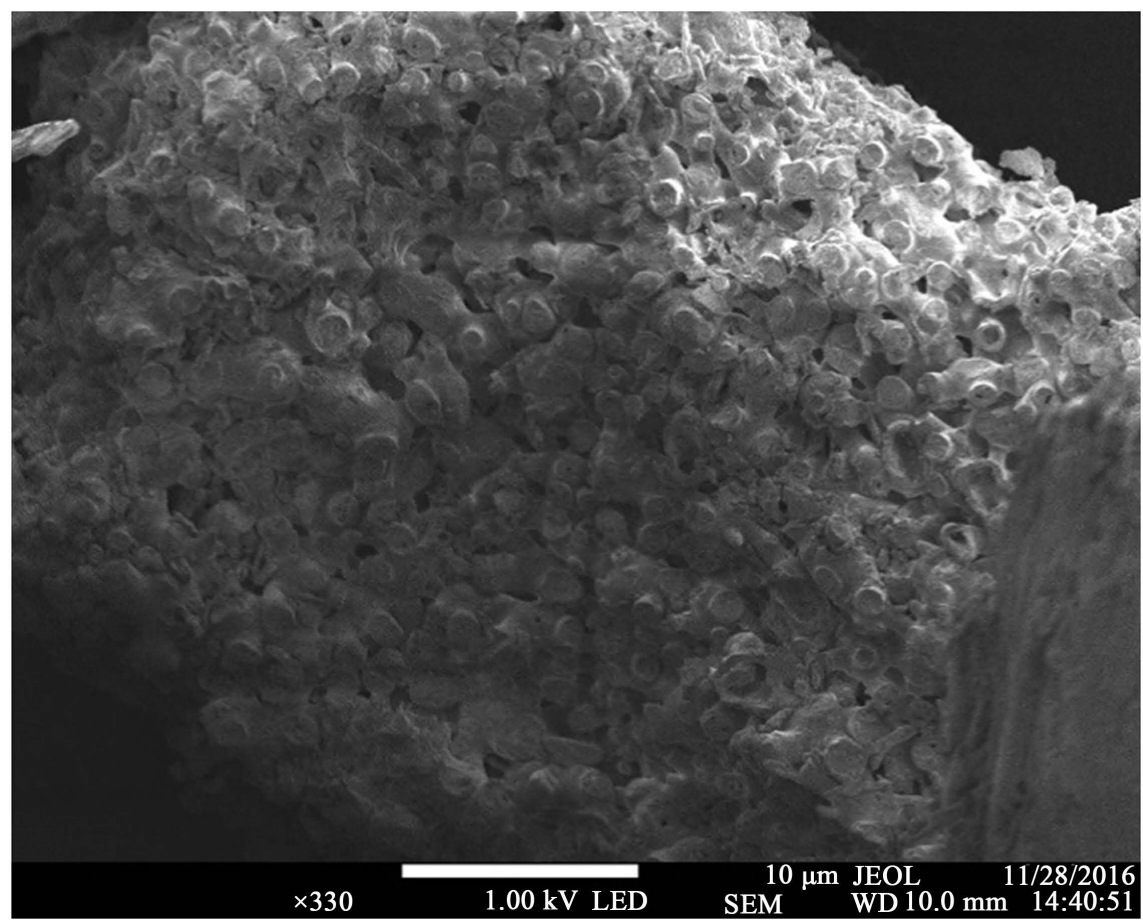

(b)

Figure 1. SEM images of the vinegar treated eggshell (VTE) (a) and ion loaded eggshell after adsorption (AEs) (b).

\subsection{Fourier Transform Infrared Spectroscopy (FT-IR)}

Figure 2 shows an FTIR of eggshells before removal (blue) and after removal (pink) of the selected ions. 


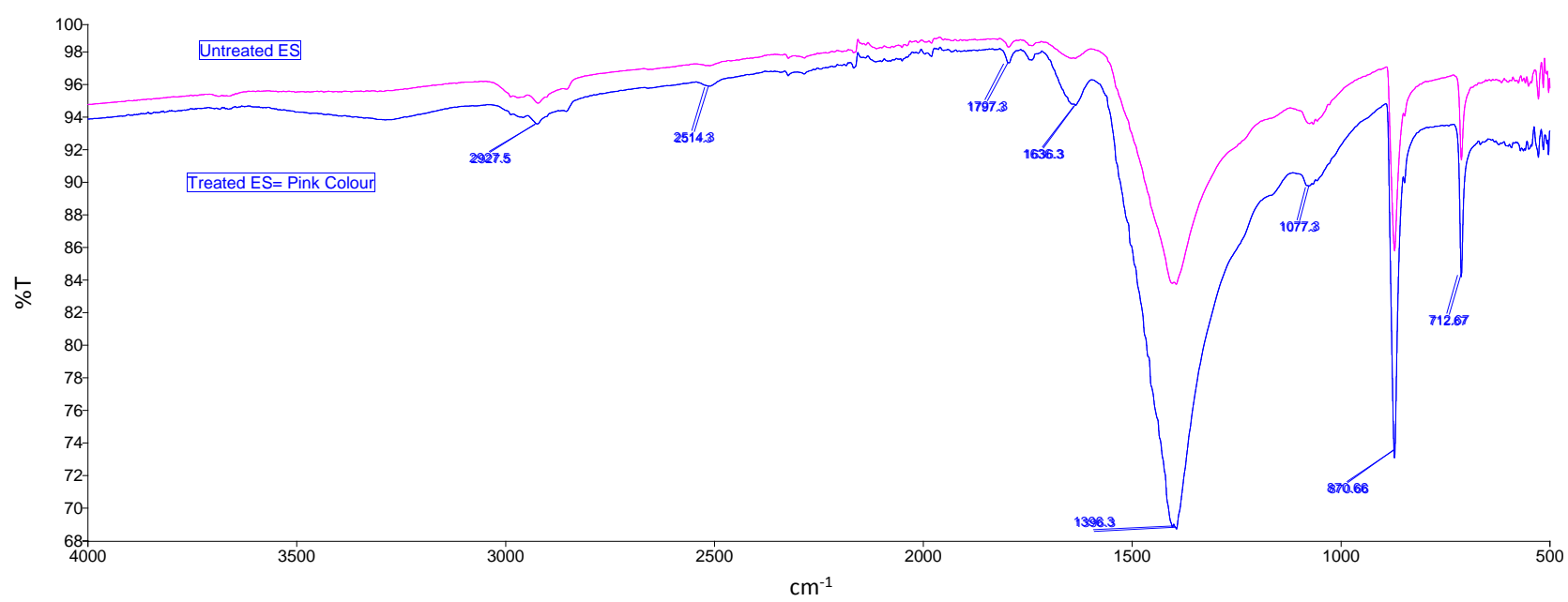

Figure 2. FTIR of Egg shells before removal (blue) and after removal pink) of target analytes.

Eggshells were mainly composed of calcium carbonate $(94.03 \%)$ and it also contains calcite and calcareous soil. They have a cellulosic structure and contain amino acids; thus, it is expected to be a good adsorbent.

The two most significant peak intensities were observed at 1396 and $870 \mathrm{~cm}^{-1}$, which were strongly associated with the presence of calcium carbonate in the eggshell matrix. The peak at $870 \mathrm{~cm}^{-1}$ confirmed the presence of valerite. A moderately observable peak at 712 indicated the in-plane and out-planes deformation modes of calcium carbonate. It has been reported that the most prominent peak in FTIR spectra of eggshell particles matched with that of carbonate minerals. The peak at $2927.5 \mathrm{~cm}^{-1}$ is due to presence of $\mathrm{C}-\mathrm{H}$ stretching mode.

\subsection{Raman Spectroscopy}

The Raman spectrograms obtained from the treated eggshells powder (TEs) and the loaded eggshells powder (AEs) are shown in Figure 3. Well-defined peaks are observed along the cross section of the scale. Characteristic peaks of the spectrograms showing the presence of calcite $\left(1130 \mathrm{~cm}^{-1}\right)$ and an amino functional group most likely from ovocleidin $17\left(785 \mathrm{~cm}^{-1}\right)$ (Corinne et al., 2011) were found in AEs and the TEs powders but with increasing intensities in the order of TEs $<$ AEs.

Hence, the eggshells are composed of calcite (mineral component) and ovocleidin (organic component). There have been reports on different kinds of eggshells from different species that indicated the same materials present on the chicken eggshells powder.

\subsection{Optimization of Adsorptive Parameters of the Eggshells}

Experimental matrices were designed using Minitab for the optimization purposes. Optimization was carried out using prepared stock solutions from the two ions (Co and $\mathrm{Ni}$ ). The yields/responses were followed by the use of ICP-OES. Two designs were used to perform the experiments were two fraction factorial and central composite designs. 

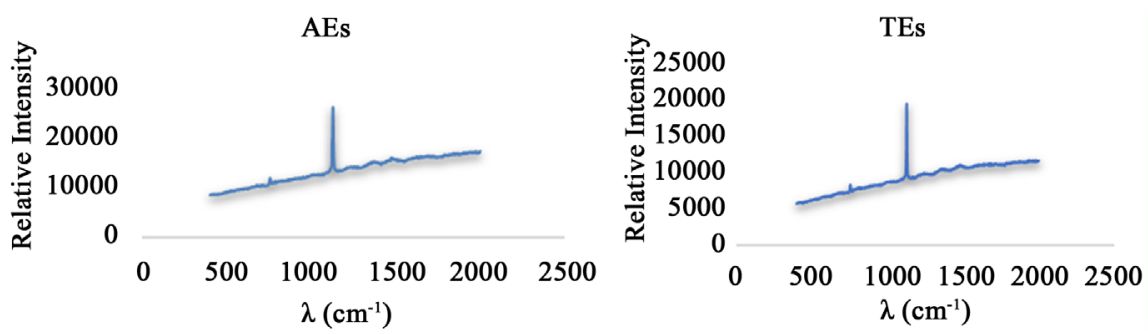

Figure 3. Raman spectrograms of the AEs and the TEs powders.

\subsection{Two-Level $1 / 2$ Fraction Factorial Design}

Prior to performing the actual optimization, a $1 \frac{1}{2}$ fraction factorial design was carried out in order to assess the level of significance of each factor investigated for. The factorial design comes as a screening phase; screening designs allow screening a relatively large number of factors in a relatively small number of experiments that cover the whole experimental domain, with the output identifying the most influential factors towards obtained yields [15] [16]. From the normal probability plot of standardized effects (Figure 4), the magnitude of the main effects of each factor as well as the effects brought about by the interaction of factors towards the obtained yield are investigated. The magnitude of each type of effect is represented by its distance from the solid line, as well as the side on which the effect lies with respect to the solid line. Negative effects lie to the left while positive effects lie to the right of the solid line. The solid line indicates where the points would fall if the effects were zero, while the percentage in the $y$-axis signifies the weightage of each factor's contribution towards the obtained yield [17]. All the investigated effects showed a positive magnitude as they all lay to the right of the graph as shown in Figure 4 below. All the four factors $\mathrm{A}$ (contact time), B ( $\mathrm{pH}), \mathrm{C}$ (sorbent dosage) and $\mathrm{D}$ (Concentration) were significant for nickel (Figure 4(a)) and cobalt (Figure 4(b)).

\subsection{Central Composite Design (CCD)}

Following the screening of significant factors using fractional factorial design, a response surface design was then created to determine the optimum conditions of each factor. This was achieved through the use of a CCD. Fractional factorial design revealed that when using VTEs all the factors investigated (Contact time, $\mathrm{pH}$, sorbent dosage and concentration) were significant. Response surfaces and the response optimizer were used to determine the optimum conditions of each factor in relation to the eggshell biomass. Table 2 and Figure 5 show the optimized parameters.

\subsection{Effect of Contact Time}

Contact time is an important parameter for determining the equilibrium time required for the sorption of metal ions on a sorbent as it is directly proportional to amount of metal ions removed from aqueous solution. It was observed that the percentage efficiency of the VTEs increases with time and subsequently reaches a constant value at the optimal time where no more ions can be ad- 


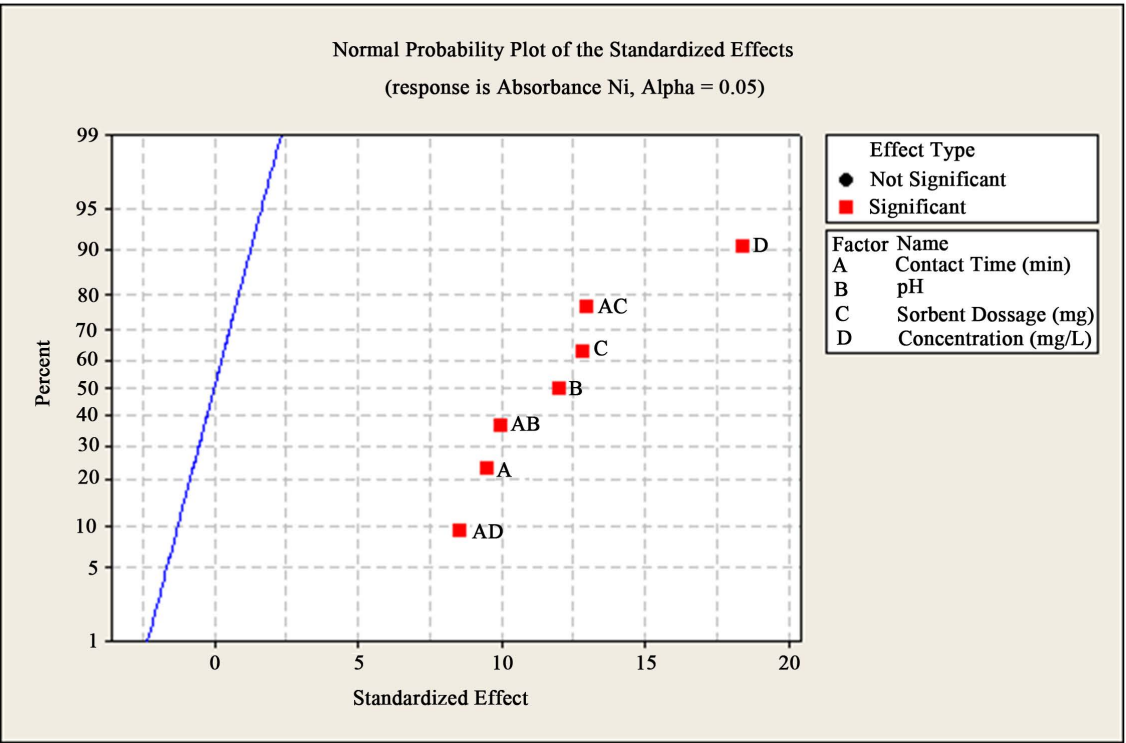

(a)

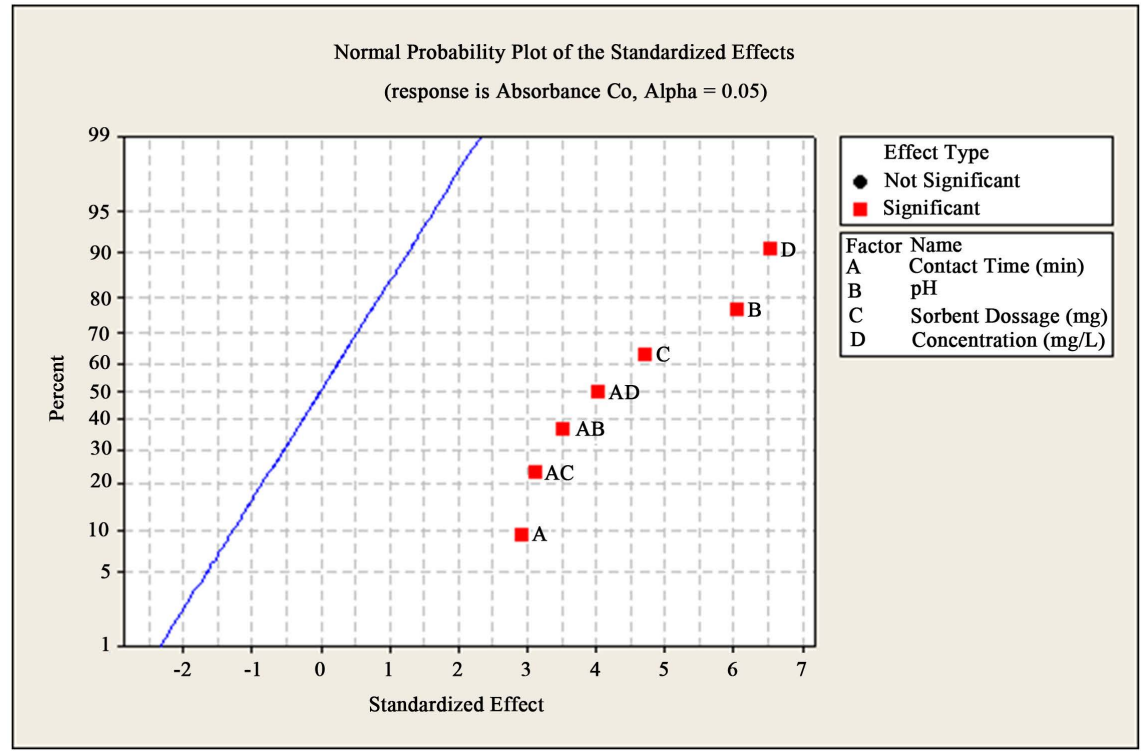

(b)

Figure 4. Normal probability plots of standardized effects showing the significant experimental factors for removal of $\mathrm{Ni}(\mathrm{a})$ and $\mathrm{Co}(\mathrm{b})$.

Optimized parameters

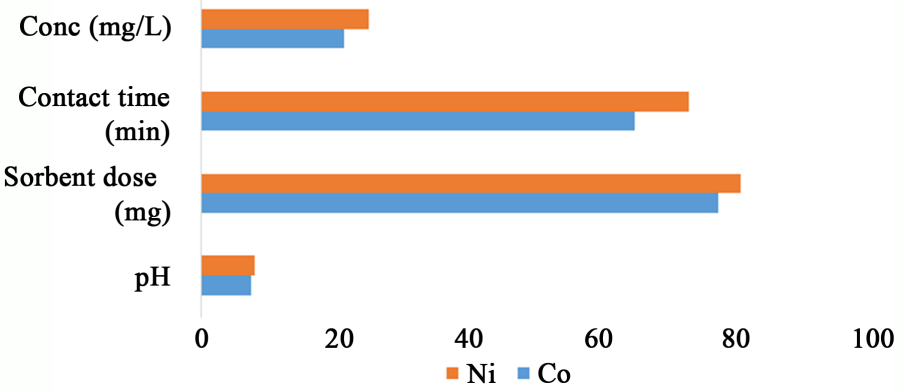

Figure 5. Optimization parameters. 
sorbed from the solution [18]. At then constant value, the amount of ions being adsorbed by the VTEs was concluded to be in a state of dynamic equilibrium with the amount of ions desorbed from the VTEs. The time required to attain this state of equilibrium is referred to as the equilibrium (optimal) time. The amount of ions adsorbed at the equilibrium time reflects the maximum adsorption capacity of the adsorbent under optimal conditions. The result showed that the adsorption of metals increases with time up to the optimal time as reflected in Table 2.

\subsection{Sorbent Dose}

It is expected that as the sorbent amount increases, the number of sorbent particles surrounding the metal ion or ratio of sorbent particle to metal ion increases [19]. Thus increasing the surface area on which the metal ions binds to the surface of the sorbents and hence increasing the removal efficiency. The adsorption of ions increased with the VTEs dosage. At VTEs dosage above the optimal dosage (see Table 2), adsorption equilibrium was reached. The percentage of ions removal increased with the increasing amount of VTEs. This may be attributed to the availability of more and more binding sites for complexation of ions. Further increment in VTEs dose did not cause significant improvement in adsorption. This seems to be due to the binding of almost all ions to the VTEs leading to equilibrium between the ions bound to the adsorbent and those remaining unadsorbed in the solution.

\subsection{Effect of $\mathrm{pH}$}

The $\mathrm{pH}$ of aqueous solution is very important in sorption processes since it affects the solubility of metal ions, concentration of the counter ions on the functional groups of the adsorbent and the degree of ionization of the sorbate during the reaction [20]. The percentage removal increased rapidly between $\mathrm{pH} 5-8.75$ and then became consistent, ranging between $80 \%$ and $98 \%$. At lower $\mathrm{pH}$ values, the adsorption efficiency was found to decrease. The low adsorption of ions at $\mathrm{pH} 2$ was due to high concentration and high mobility of $\mathrm{H}+$ ions, which competed with metal ions for the adsorption sites, hindering the adsorption of cations by VWMs. Meanwhile, at $\mathrm{pH} 9$ - 10, adsorption was also low especially for the anions, due to the high concentration and high mobility of $\mathrm{OH}-$, which competed with the anions. Protonated adsorption sites were incapable of binding cations due to electrostatic repulsion between positively charged cations and positive charged sites. Hence, only low percentages of cations were adsorbed. As the $\mathrm{pH}$ increased, there were fewer $\mathrm{H}^{+}$ions present in the solution and consequently more negatively charged sites were made available and this facilitated greater cations uptake by electrostatic attraction.

\subsection{Effect of Varying Concentration of Ions}

The rate of adsorption is a function of initial concentration of ions. The initial concentration provides an essential driving force to overcome all mass transfer 
resistance of metal ions between the aqueous and the solid sorbent. It was observed that at higher adsorption was found to take place at lower concentrations. This is due to the interaction of all the ions present in the solution with binding sites on the VTEs surface. At higher concentrations, more ions are left unadsorbed in the solution due to saturation of adsorption sites. The number of ions adsorbed from a solution of higher concentrations is more than that removed from less concentrated solutions. At lower ions concentration, the percentage removal was higher due to larger surface area of adsorbent being available for adsorption [21]. When the concentration of ions increases, the percentage removal decreased due to a decrease in available sites for adsorption which is as a result of saturation of adsorption sites. At a higher concentration of ions, the ratio of initial number of moles of ions to the adsorption sites available was higher, resulting in lower adsorption percentage.

Meanwhile, with the increasing initial ions concentration from $0 \mathrm{mg} / \mathrm{L}$ to 50 $\mathrm{mg} / \mathrm{L}$, the amount of ions adsorbed at equilibrium increased. This phenomenon is due to increase in driving force of the concentration gradient to overcome all mass transfer resistance of ions between aqueous and solid phases and accelerate the probable collision between ions and VTEs, thus resulting in higher removal of ions.

\subsection{Determination of Anions and Cations within the Wastewater Sample}

The main water source for local people in Botswana is underground waters from local boreholes but most of the boreholes have low capacity. The supply does not meet the demands for irrigation. Around the Glen Valley Wastewater treatment plant, irrigation schemes using the wastewater from the plant have been set up. Due to these factors, borehole and wastewater samples were ideal to be used as the real water samples in this work. The initial total ions concentrations $(\mathrm{mg} / \mathrm{L})$ from the digested wastewater samples were determined as shown in Table 3. Figure 6 shows the comparison of $\mathrm{Ni}$ and Co levels in waste water. Cobalt was in higher concentration and this can be due to the natural and industrial sources. For instance, from soil, dust, burning coal, oil, from car, truck and other industrial processes that use the metal or its compounds.

The metal concentrations in all the sampling points in the wastewater treatment plant were found to be within the allowed levels which are set by waste water specification-BOBS 93:2012 in Botswana and US EPA [22] [23].

\subsection{Application of the Optimized Adsorption Method to Real Samples}

After determining the optimum parameters as shown in Table 2, the parameters

Table 3. Concentration of the metal ions in wastewater.

\begin{tabular}{ccc}
\hline & Co & Ni \\
\hline Wastewater & $0.342 \pm 0.0023$ & $0.271 \pm 0.0081$ \\
\hline
\end{tabular}


were applied in a $50 \mathrm{~mL}$ of the wastewater sample and the resulting solution was analyzed using ICP-OES. The percentage removal of ions was calculated using the formula below

$$
\frac{C_{i}-C_{f}}{C_{i}} \times 100 \%
$$

where:

$C_{i}$ is the initial concentration of metal ions in wastewater sample;

$C_{f}$ is the final concentration of metal ion in wastewater after applying the eggshell biomass.

Figure 7 represents the percentage removal of Co (78.70) and Ni (76.53).

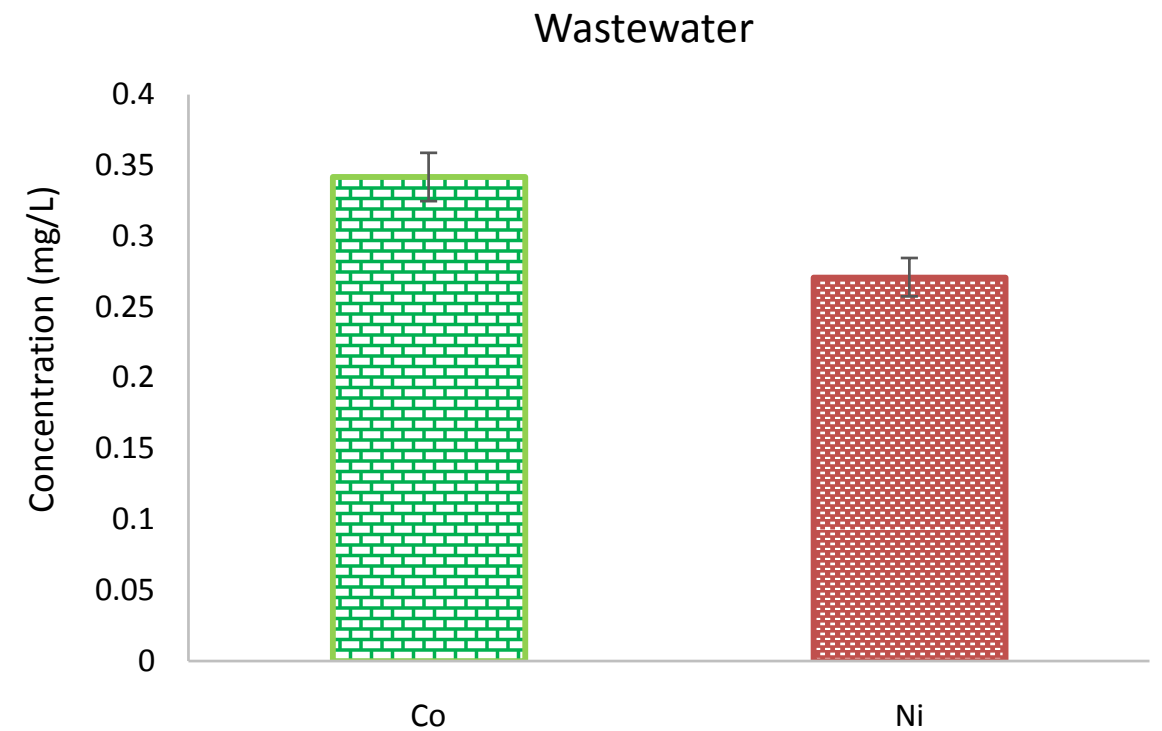

Figure 6. Concentration of Cobalt and Nickel in wastewater.

TES Treatment

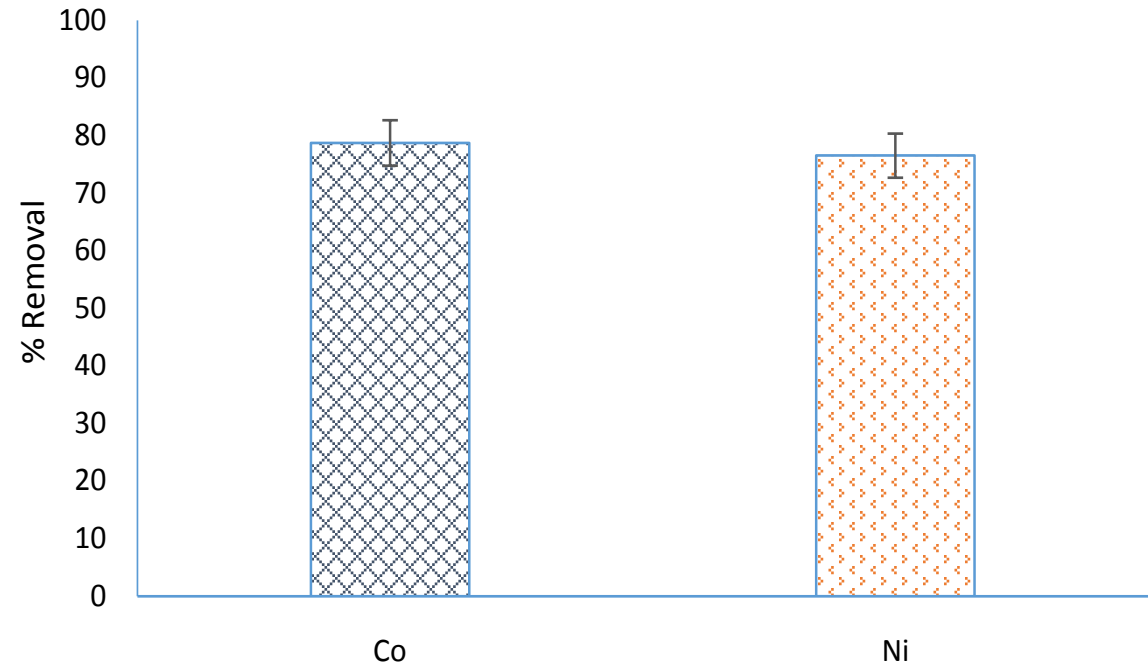

Figure 7. Percentage removal of Cobalt and Nickel from wastewater using treated eggshell biomass. 


\section{Conclusion}

In this study, an attempt to add value to waste material by developing an eco-friendly method for removing $\mathrm{Ni}^{2+}$ and $\mathrm{Co}^{2+}$ ions from wastewater was conducted. Adsorption studies were developed and evaluated. These studies demonstrated that $\mathrm{pH}$, sorbent dose, contact time and concentration are significant factors in adsorption. Treating the eggshells with vinegar was found to be a green method therefore conserving the environment. Vinegar-treated eggshells were proposed as cheap, easily available and efficient method for removal of heavy metals from the environment.

\section{Acknowledgements}

Thank you to BIUST for covering publication costs, University of Botswana for providing work space and some instruments.

\section{Conflict of Interest}

The authors declare no conflict of interest. The founding sponsors had no role in the design of the study; in the collection, analyses, or interpretation of data; in the writing of the manuscript, and in the decision to publish the results.

\section{References}

[1] Dawson, M. and Macklin, E.J. (1998) Speciation of Heavy Metals in Floodplain and Flood Sediments: A Reconnaissance Survey of the Aire Valley, West Yorkshire, Great Britain. Environmental Geochemistry and Health, 20, 67-69. https://doi.org/10.1023/A:1006541724394

[2] Braam, A. and Klapwijk, F. (1981) Effect of Copper on Nitrification in Activated Sludge. Water Research, 15, 1093-1098.

https://doi.org/10.1016/0043-1354(81)90077-4

[3] Waara, K.O. (1992) Effects of Copper, Cadmium, Lead and Zinc on Nitrate Reduction in a Synthetic Water Medium and Lake Water from Northern Sweden. Water Research, 26, 355-364. https://doi.org/10.1016/0043-1354(92)90032-Y

[4] Dilek, U. and Yetis, F.B. (1992) Effects of Heavy Metals on Activated Sludge Process. Water Sci. Technol., 26, 80-813.

[5] Imai, E.F. and Gloyna, A. (1990) Effects of $\mathrm{pH}$ and Oxidation State of Chromium on the Behaviour of Chromium on Activated Sludge Process. Water Research, 24, 1143-1150. https://doi.org/10.1016/0043-1354(90)90178-9

[6] Surittanonta, J.H. and Sherrad, S. Activated Sludge Nickel Toxicity Studies. J.Water Pollut. Control Fed, 53, 1314-1322.

[7] Fu, F.L. and Wang, Q. (2011) Removal of Heavy Metal Ions from Wastewaters. Journal of Environmental Management, 92, 407-418. https://doi.org/10.1016/j.jenvman.2010.11.011

[8] Hegazi, H.A. (2013) Removal of Heavy Metals from Wastewater Using Agricultural and Industrial Wastes as Adsorbents. HBRC Journal, 9, 276-282.

https://doi.org/10.1016/j.hbrcj.2013.08.004

[9] Rao, T.P., Kala, R. and Daniel, S. (2006) Metal Ion-Imprinted Polymers-Novel Materials for Selective Recognition of Inorganics. Analytica Chimica Acta, 578, 105 116. https://doi.org/10.1016/j.aca.2006.06.065 
[10] Boyer, T.H. and Singer, P.C. (2005) Bench-Scale Testing of a Magnetic Ion Exchange Resin for Removal of Disinfection By-Product Precursor. Water Research, 39, 1265-1276. https://doi.org/10.1016/j.watres.2005.01.002

[11] And, Y.E., El-Nahhal, I.Y. and Al-Najar, H. (2014) Cations and Anions in Sewage Sludge from Gaza Waste Water Treatment Plan. 655-665.

[12] Barakat, M.A. (2011) New Trends in Removing Heavy Metals from Industrial Wastewater. Arabian Journal of Chemistry, 4, 361-377.

[13] Maina, I.W., Obuseng, V. and Nareetsile, F. (2016) Use of Moringa oleifera (Moringa) Seed Pods and Sclerocarya birrea (Morula) Nut Shells for Removal of Heavy Metals from Wastewater and Borehole Water. Journal of Chemistry, 2016, Article ID: 9312952. https://doi.org/10.1155/2016/9312952

[14] Nadeem, M., Mahmood, A., Shahid, S.A., Shah, S.S., Khalid, A.M. and McKay, G. (2006) Sorption of Lead from Aqueous Solution by Chemically Modified Carbon Adsorbents. Journal of Hazardous Materials, 138, 604-613.

[15] Pokhrel, D. and Viraraghavan, T. (2006) Arsenic Removal from Aqueous Solution by Iron Oxide-Coated Fungal Biomass: A Factorial Design Analysis. Water, Air, \& Soil Pollution, 173, 195-208. https://doi.org/10.1007/s11270-005-9056-Z

[16] Ponnusami, V., Krithika, V., Madhuram, R. and Srivastava, S.N. (2007) Biosorption of Reactive Dye Using Acid-Treated Rice Husk: Factorial Design Analysis. Journal of Hazardous Materials, 142, 397-403.

[17] Ryan, T.P. (2006) Modern Experimental Design. Wiley, Hoboken, 8608, 1-601.

[18] Ahmad Panahi, H., Samadi Zadeh, M., Tavangari, S., Moniri, E. and Ghassemi, J. (2012) Nickel Adsorption from Environmental Samples by Ion Imprinted Aniline Formaldehyde Polymer. Iranian Journal of Chemistry and Chemical Engineering, 31, 35-44.

[19] Kamel, A.H., Moreira, F.T.C., Almeida, S.A.A. and Sales, M.G.F. (2008) Novel Potentiometric Sensors of Molecular Imprinted Polymers for Specific Binding of Chlormequat. Electroanalysis, 20, 194-202. https://doi.org/10.1002/elan.200704039

[20] Zhao, J., Han, B., Zhang, Y. and Wang, D. (2007) Synthesis of Zn(II) Ion-Imprinted Solid-Phase Extraction Material and Its Analytical Application. Analytica Chimica Acta, 603, 87-92.

[21] Birlik, E., Ersöz, A., Açikkalp, E., Denizli, A. and Say, R. (2007) Cr(III)-Imprinted Polymeric Beads: Sorption and Pre-Concentration Studies. Journal of Hazardous Materials, 140, 110-116.

[22] Report, M. (2013) Republic of Botswana Botswana Integrated Water Resources Management \& Water Efficiency Plan. Gaborone.

[23] U.-EPA (1992) EPA Guidelines for Water Reuse. 126-129. 
Submit or recommend next manuscript to SCIRP and we will provide best service for you:

Accepting pre-submission inquiries through Email, Facebook, LinkedIn, Twitter, etc. A wide selection of journals (inclusive of 9 subjects, more than 200 journals)

Providing 24-hour high-quality service

User-friendly online submission system

Fair and swift peer-review system

Efficient typesetting and proofreading procedure

Display of the result of downloads and visits, as well as the number of cited articles Maximum dissemination of your research work

Submit your manuscript at: http://papersubmission.scirp.org/

Or contact jwarp@scirp.org 